\title{
Aplicabilidade da Teoria das Restrições: Um Estudo dos Métodos de Gerenciamento da Produção em Indústrias
}

\author{
João Vitor Batista Simões ${ }^{1}$; Antonio Raniel Silva Lima
}

\begin{abstract}
Resumo: A presente pesquisa se caracteriza como revisão bibliográfica sistemática que se propõe em ampliar o estudo sobre o tema Teoria das Restrições a partir da análise de produções acadêmicas, mais especificamente artigos científicos que aplicaram os conceitos da TOC (Theory of Constraints) em diversos setores da indústria, para a observação dos métodos utilizados e os resultados alcançados em cada pesquisa. Os artigos foram pesquisados em sites de periódicos de acesso aberto (Spell, Scielo e DOAJ), e realizado a filtragem para os critérios predefinidos, encontrando 06 artigos para análise. Apesar de que alguns estudos não foram implantados de forma efetiva, apenas propuseram a implantação dos conceitos nos meios de estudo, foi observado que a TOC proporciona ganhos evidentes através de ferramentas e métodos específicos propostos pela teoria, adequados em cada caso estudado, bem como a utilização do processo de raciocínio como um todo, contribuindo para os resultados das organizações.
\end{abstract}

Palavras-Chave: Indústria. Teoria das Restrições. Gargalo. Gestão da produção

\section{Applicability of Restriction Theory: A Study of the Production Management Methods in Industries}

\begin{abstract}
The present research is characterized as a systematic bibliographical review that proposes to expand the study on the theme of the Theory of Constraints from the analysis of academic productions, more specifically scientific articles that applied the concepts of TOC (Theory of Constraints) in several sectors of the industry, for the observation of the methods used and the results achieved in each research. The articles were searched on open access journals sites (Spell, Scielo and DOAJ), and the filtering was performed for the predefined criteria, finding 06 articles for analysis. Although some studies were not implemented in an effective way, only proposed the implementation of the concepts in the study means, it was observed that TOC provides evident gains through specific tools and methods proposed by the theory, adequate in each case studied, as well as use of the reasoning process as a whole, contributing to the results of organizations.
\end{abstract}

Keywords: Industry. Theory of Constraints. Bottleneck. Production Management

\section{Introdução}

A otimização da produção uma vez aplicada de forma eficiente pode trazer uma grande vantagem competitiva em relação à produtividade, uma forma de aplicar essa otimização é por

\footnotetext{
${ }^{1}$ Graduando em Administração, Centro Universitário Doutor Leão Sampaio, Juazeiro do Norte, Ceará, jvitorsimoes3@ gmail.com ${ }^{2}$ Especialista em Gestão Financeira, Centro Universitário Doutor Leão Sampaio, Juazeiro do Norte, Ceará, raniel@ @eaosampaio.edu.br

282 Id on Line Rev. Mult. Psic. V.12, N. 42, Supl. 1, p. 282-299, 2018 - ISSN 1981-1179
Edição eletrônica em http://idonline.emnuvens.com.br/id
} 
meio da Teoria das Restrições (TOC) constituída e difundida pelo físico israelense Eliyahu Goldratt na década de 70. Segundo Goldratt (1996), todo sistema produtivo possui ao menos uma restrição que impede a elevação do seu desempenho. Essas restrições devem ser trabalhadas para que a empresa alcance suas metas.

A partir do atual cenário competitivo onde as empresas atuam, é de importância a visão da melhoria contínua dos processos para a minimização das dificuldades que implicam diretamente nos objetivos das empresas. Juntamente com a alta demanda e clientes mais exigentes, é necessário um aumento produtivo de capacidade, sem perda de qualidade, onde se torna um dilema para muitas indústrias.

Diante dos problemas que são encontrados em um sistema produtivo (alta demanda, ineficiência produtiva, dentre outros.), e analisando a teoria das restrições (TOC) como processo de melhoria, observa-se a necessidade de observação e análise de como as empresas lidam com tais gargalos, e qual a tomada de decisão referente à otimização da produção, tomando por base o estudo em produções acadêmicas baseadas na Teoria das Restrições aplicada em indústrias de diversos setores (calçados, metalúrgica, alimentação etc.). A partir do contexto, formula-se o seguinte questionamento para a elaboração e exploração do conteúdo para possíveis conclusões: Como a aplicação da Teoria das Restrições pode influenciar nos resultados e quais os métodos utilizados para o alcance das metas de produção industrial?

A presente pesquisa, se propõe em observar e analisar os métodos de gestão da produção aplicados em diversos setores da indústria a partir da revisão de trabalhos científicos aplicados em meios industriais baseados na Teoria das Restrições.

A partir do referencial teórico, apresenta-se contextos, explicando a evolução histórica da Teoria das Restrições, a identificação das principais restrições em um sistema produtivo, a identificação e classificação dos conceitos da TOC na cadeia produtiva assim como o método tambor-pulmão-corda. Em seguida os métodos utilizados para a realização da pesquisa, e por fim os resultados e conclusões obtidos através da mesma.

Com o estudo realizado, há a contribuição para uma nova abordagem, consequentemente servindo de base para novos estudos sobre o tema. Organizações também podem tomar base por essa pesquisa para o estudo e aplicação em seus processos.

283 Id on Line Rev. Mult. Psic. V.12, N. 42, Supl. 1, p. 282-299, 2018 - ISSN 1981-1179 Edição eletrônica em http://idonline.emnuvens.com.br/id 
A presente pesquisa surgiu da curiosidade da aplicação de um sistema de produção, onde a maioria das empresas (de forma genérica) não utiliza, bem como a verificação do desempenho, quando se há a utilização de tais conceitos.

\section{Teoria das Restrições (TOC)}

No início dos anos 70, Eliyahu Goldratt ainda estudante de física, desenvolveu um sistema de planejamento para um amigo, na fabricação de gaiolas para aves. A partir desse desenvolvimento, foi possível dar base ao sistema OPT (Optimized Production Technology), voltado à programação da produção. Dessa forma, Goldratt foi adaptando uma série de princípios de melhoria ao sistema OPT, desenvolvendo por fim a Teoria das Restrições (Theory of Constraints - TOC). A TOC pode ser entendida como a ampliação do pensamento da tecnologia de produção otimizada. (GUERREIRO, 1996).

A TOC foi inicialmente descrita pelo físico Israelense Eliyahu Moshe Goldratt em seu livro “A Meta” em 1984, onde ressalta a importância da gestão das restrições em um sistema para o alcance das metas. (VIDAL e WANKE, 2009).

Uma restrição é qualquer coisa que limite um sistema de atingir um desempenho superior em relação à sua meta (GOLDRATT, 1996). Dessa forma, o desempenho do sistema será determinado pelas restrições. Para tanto, "a meta de uma empresa precisa estar claramente estabelecida para que se possa definir os medidores de desempenho, tanto da empresa como dos diversos departamentos que a formam". (CHECOLI, 2000, p.26). Ainda assim, Corbett (2005) ressalta que para a TOC, sempre haverá restrições no sistema, caso contrário, o desempenho da mesma seria infinito.

A meta de uma empresa, segundo Goldratt (1990), consiste em "ganhar dinheiro" no presente e no futuro. É o objetivo maior da empresa, porém a meta não pode ser mensurada diretamente, deve-se atentar a alguns indicadores para a verificação da relevância de que certas tomadas de decisões estão direcionando à meta: Lucro Líquido, Retorno sobre o investimento, e Fluxo de caixa.

Em contrapartida, Guerreiro (1996) ressalta que a meta corresponde ao propósito global da organização, ainda que Goldratt argumente que a meta pode e deve ser estabelecida pelos 
proprietários, a empresa deve ser visualizada como uma máquina de fazer dinheiro e o principal propósito seria ganhar dinheiro hoje e sempre.

De acordo com Verma (1997), a Teoria das Restrições pode ser definida como um método de gestão voltado para a melhoria contínua, minimizando os fluxos de produção e voltando-se para o melhoramento do desempenho das operações. Assim, a TOC busca o aperfeiçoamento da produção através da identificação de recursos que limitam o sistema produtivo.

Goldratt (1996) releva a premissa de que "mais é melhor", porém essa afirmação não se vale para um sistema como um todo: Em recursos com capacidade de restrição, essa premissa se cabe perfeitamente. Em contrapartida, a aplicação da afirmativa em recursos não-gargalos em um certo limiar, "mais" se tornaria pior. Para que a empresa tenha sucesso em suas metas, tem-se que definir tais recursos gargalos no sistema produtivo e manuseá-los de forma que se tenha melhor proveito da capacidade para consequentemente se ter melhor desempenho.

Segundo Wanke (2004) as restrições podem se classificar como físicas e não-físicas. As restrições físicas se caracterizam por serem tangíveis, como por exemplo: máquinas, veículos, instalações, equipamentos e outros. Por outro lado, as não-físicas podem ser procedimentos corporativos, demanda de um produto, processos complexos, ou paradigmas mentais.

\section{Etapas da TOC}

A Teoria das Restrições pode ser aplicada em cinco passos para o processo decisório, visando à melhoria contínua dos processos, onde permitem compreender o ambiente e planejar o processo de implementação e retroalimentação da TOC, denominada "Método de Focalização em 5 etapas" (COX III e SPENCER, 2002). Segundo a TOC esses 5 passos consistem em:

\section{- Identificar a Restrição:}

Quando se tem maior demanda total, em relação à capacidade da fabricação, tem-se um RRC - Recurso com Restrição de Capacidade, denominado também de gargalo, ou restrição (CORBETT 1997). Esses gargalos ou restrições devem ser identificados no sistema produtivo para serem trabalhados de maneira diferente dos recursos não-gargalos. 


\section{- Explorar a Restrição:}

Depois de identificada a restrição do sistema, é necessário que haja a exploração da restrição, ou seja, a utilização da melhor maneira para que não haja perdas de produção, maximizando o ganho no gargalo. Ainda que uma hora perdida no gargalo, é igual a uma hora perdida em todo o sistema produtivo. (GOLDRATT, 1990).

\section{- Subordinar à Restrição:}

Consiste em fazer com que todo restante do processo de produção se volte à restrição, os outros recursos não-gargalos devem trabalhar no mesmo ritmo da restrição para que não haja excesso de capacidade, possibilitando a redução dos inventários e das despesas operacionais, garantindo o ganho do sistema de produção. Para essa etapa, vale-se ressaltar a premissa estabelecida por Goldratt (1990) onde ressalta que uma hora economizada em recursos nãogargalos, é apenas uma ilusão.

\section{- Elevar a Restrição:}

Deve-se aumentar a capacidade do RRC (Recurso com Restrição de Capacidade), seja ela física ou não-física, para aumento consequente do sistema produtivo. Essa etapa pode ser explorada por uma série de decisões que uma empresa pode tomar, como por exemplo: Compra de uma nova máquina, aumento de tempo disponível para produção, redução de tempo de setup da restrição, entre outros. Dessa forma a restrição deixará de existir e o desempenho do sistema aumentará até certo limite, quando um novo recurso se tornar restrição e limitar a capacidade produtiva.

\section{- Identificar nova Restrição:}

Segundo Corbett (2005) nenhum sistema de produção está livre de restrições, pois assim, não haveria limites para o desempenho da mesma, sempre haverá algo que limite esse desempenho. Dessa forma, quando uma restrição no sistema deixar de se caracterizar como RRC, deve-se identificar uma nova restrição para ser trabalhada novamente e realizar um ciclo contínuo de melhoramento, sem que a produção se torne uma inércia e venha a esta, ser uma restrição a mais. 


\section{Método Tambor-Pulmão-Corda (TPC)}

Inserida na Teoria das Restrições, o método TPC relaciona-se com os fatores que impulsionam um sistema produtivo levando em conta as restrições, os estoques e recursos envolvidos em conjunto para maior rentabilidade como um todo. Dessa forma, pode-se dizer que tal método, é utilizado para representar a TOC de maneira mais resumida e objetiva. "A operacionalização do planejamento pela TOC em um programa de produção ocorre através do método DBR.” (WANKE, 2009, p.7).

Partindo do pressuposto estabelecido por Goldratt (1996) onde toda restrição é o recurso que limita o sistema de alcançar maior desempenho e que todo sistema produtivo deve-se subordinar à restrição, tem-se que esse gargalo irá comandar o restante dos recursos a ele amarrados, por essa razão, dá-se o nome de tambor, onde a restrição dita o ritmo que o sistema deve trabalhar. Segue ilustração abaixo para exemplificação:

Figura 01 - Modelo TPC

$20 \mathrm{Min}$

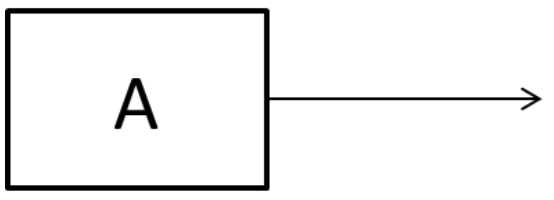

2 Horas

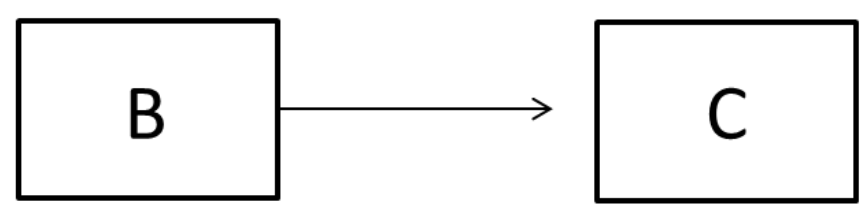

Fonte: Autores
1 Hora

É perceptível que o posto que leva mais tempo para processar uma unidade nesse sistema é o B, portanto ele pode ser considerado o gargalo ou o tambor do sistema, uma vez que os outros postos deverão também trabalhar no ritmo do gargalo para que não exceda a produção e acabe por acumular estoque excedente. A título de exemplo, o posto A poderá operar por uma hora produzindo 3 peças e parar enquanto o posto B não requerer mais peças, já que uma única peça produzida no posto B leva 2 horas, e o posto $\mathrm{C}$ também será subordinado, não necessitando sua capacidade total.

O posto A, como leva menos tempo para processar, reserva sempre um certo estoque antes do próximo posto quando trabalhado da maneira correta, esse estoque é chamado de 
pulmão, é a reserva de estoque suficiente para o tambor trabalhar, já que ele precisamente não deverá estar inoperante para maior capacidade produtiva do sistema. "Em linhas gerais o Pulmão é criado para proteger a programação. É uma antecipação do instante de liberação dos itens de modo a garantir o cumprimento do programa de produção.” (WANKE, 2009, p.2).

Dessa forma o tambor sempre trabalha em sua capacidade máxima sem que haja ociosidade por meio do pulmão, e subordinando os outros recursos não-gargalos para que não haja excedente de produção. Para a junção destes fatores, existe a corda onde irá "amarrar" os recursos ao gargalo e puxar as informações necessárias para que o sistema ande em conjunto.

A seguir, mostra-se um vocabulário com os principais termos e conceitos que englobam a Teoria das Restrições para uma melhor visualização afim de facilitar o entendimento mostrando de forma resumida os significados mais específicos dentro do campo de estudo:

Tabela 01 - Vocabulário

\begin{tabular}{|c|l|}
\hline Termos & \multicolumn{1}{|c|}{ Conceitos } \\
\hline Restrição & $\begin{array}{l}\text { Qualquer coisa que limite um sistema de atingir } \\
\text { um desempenho superior em relação à sua meta }\end{array}$ \\
\hline Gargalo & $\begin{array}{l}\text { Processo em que há a diminuição de fluxo de } \\
\text { produção }\end{array}$ \\
\hline RRC & Recurso com restrição de capacidade \\
\hline Meta & $\begin{array}{l}\text { A meta de uma empresa sempre será ganhar } \\
\text { dinheiro no presente e no futuro }\end{array}$ \\
\hline Teoria das Restrições & $\begin{array}{l}\text { Método de gestão voltado para a melhoria } \\
\text { contínua, minimizando os fluxos de produção e } \\
\text { voltando-se para o melhoramento do desempenho } \\
\text { das operações }\end{array}$ \\
\hline $\begin{array}{c}\text { Tambor-Pulmão-Corda } \\
\text { (TPC) }\end{array}$ & $\begin{array}{l}\text { Método voltado à produção puxada, utilização } \\
\text { resumida e objetiva da TOC }\end{array}$ \\
\hline $\begin{array}{c}\text { Optimized production } \\
\text { Tecnology (OPT) }\end{array}$ & $\begin{array}{l}\text { Sistema de gestão a partir da identificação, } \\
\text { gerenciamento e resolução de gargalos }\end{array}$ \\
\hline
\end{tabular}

Fonte: Eliyahu Goldratt (1996). Adaptado por autores.

\section{Tomada de Decisão}

Alguns pressupostos como competitividade, redução do ciclo de vida dos produtos, clientes mais exigentes entre outros, fazem com que as empresas necessitem de flexibilidade a 
ponto de gerenciar e ter certo domínio sobre tais fatores que possam vir a limitar a capacidade da organização, caso ela não venha a ter poder de decisão correta. (BORGES; MARQUES, 2011). Dessa forma, a TOC vem a simplificar uma forma de tomada de decisão em relação ao sistema produtivo, ainda que não deixe a desejar quando se fala em flexibilidade e satisfação do cliente, uma vez que essa forma de gerenciamento envolve vários fatores pertinentes à competição, onde pode promover uma ampla vantagem frente aos sistemas que não aderem tais decisões.

\footnotetext{
Alguns sistemas funcionam bem por um tempo, mas depois fracassam. Outros simplesmente não funcionam. Aqueles que parecem funcionar por um tempo, frequentemente, tendem a fracassar em momentos inesperados - como a expedição para um cliente importante. (COX III; SPENCER, 2002, p.27).
}

Para o gerenciamento das decisões e por consequência a implementação da mudança propriamente dita, caso não haja um líder comprometido, uma infraestrutura adequada e recursos de apoio à mudança, é necessário planejamento e esforços para adquirir esses recursos e infraestrutura capaz de oferecer a flexibilidade. (DUCATTI, 2014). Por outro lado, Choi (2011) relata que a incapacidade de muitas organizações para o alcance dos objetivos estabelecidos, pode ser considerada como falha de implementação e não falhas inatas à incapacidade da mudança.

\section{Aplicação em Ambientes de Manufatura}

Como já discutido, a TOC é um método de produção bastante antigo, porém nãoultrapassado, pois as ferramentas que nela estão inseridas são aplicadas direta ou indiretamente nos sistemas produtivos até hoje, bem como os estudos sobre a aplicação da teoria de maneira prática em empresas. Noreen, Smith e Mackey (1996, apud SOARES 2009) citam casos de aplicações da Teoria das Restrições em diversos segmentos, como o setor de tecidos, ferramentas, gráficas, indústria de enlatados. Martins (2002) Relata casos de aplicação no Brasil em indústrias de autopeças, setor bancário, instituições acadêmicas.

Em âmbito atual, algumas pesquisas de aplicação da teoria também se fazem presentes, como López e Grasel (2016) que aplicam os conceitos da TOC em uma unidade fabril da 
indústria metalúrgica, Souza e Pires (2014) que estudam e conceituam as ferramentas da teoria em ambientes de produção para estoque. Lacerda et al. (2016) aplicam a corrente crítica da TOC em uma refinaria de petróleo. Assim, evidencia-se um considerável número de pesquisas, através da avaliação dos resultados obtidos, e a influência desses conceitos aplicados em diversos setores.

Fernandes et al. (2009) Ressalta que alguns estudos envolvem a aplicação do conceito sob forma de simulação, ao invés da aplicação prática de forma efetiva, que poderia proporcionar uma observação mais abrangente abrindo maiores perspectivas de estudos, através da interação entre empresas e academia, proporcionando maior disseminação do conteúdo, bem como o aprofundamento do conhecimento e da experiência entre ambos.

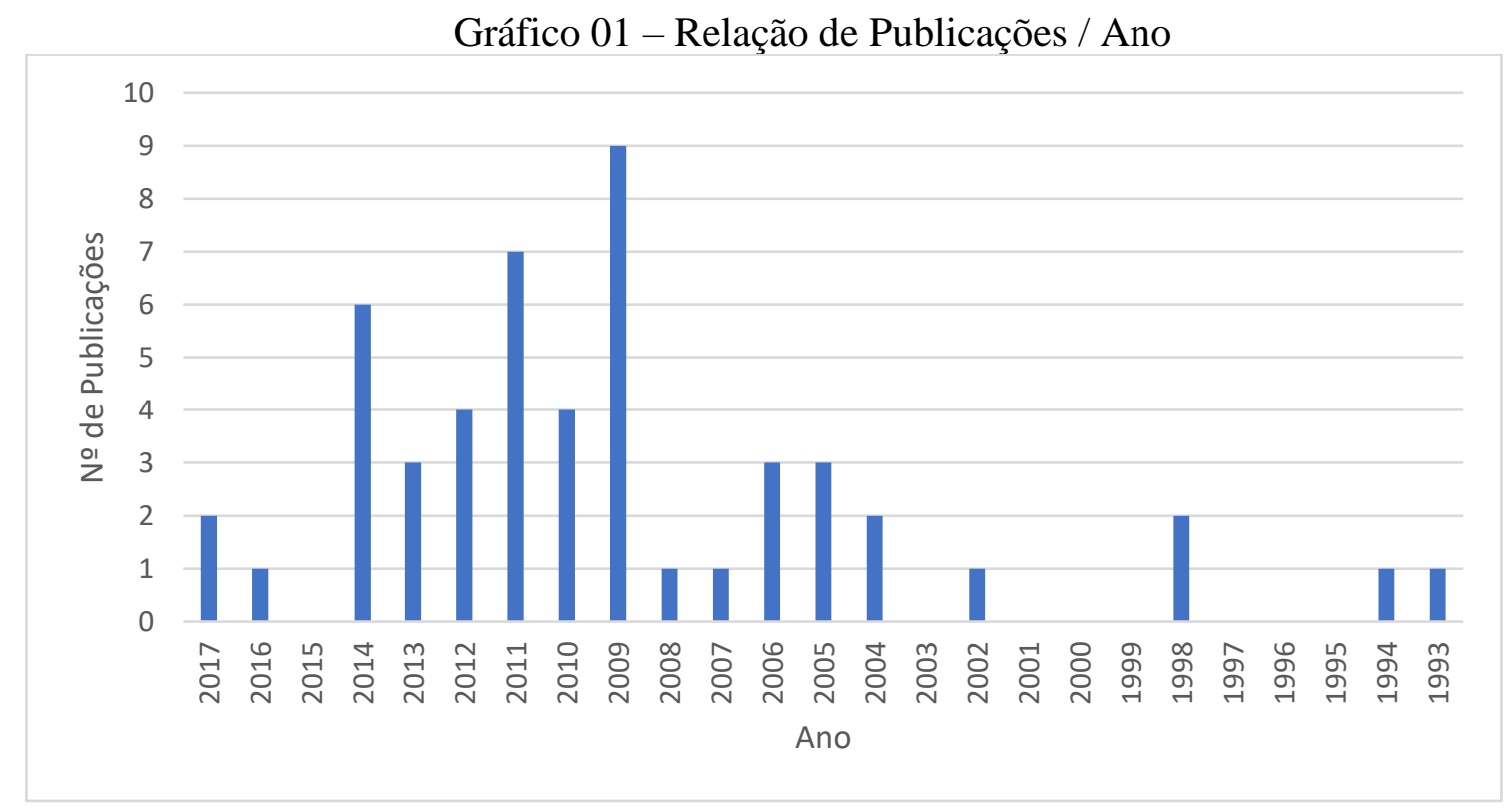

Fonte: Sites de periódicos de acesso aberto. Adaptado por Autores

É perceptível um considerável número de publicações sobre o tema, desde o ano de 1993 até 2017 há registros sobre as pesquisas acadêmicas sobre a TOC (Pesquisadas a partir dos critérios e nas bases que serão mostradas adiante, que embasaram a presente pesquisa). As produções acadêmicas são de suma importância para a disseminação do conceito servindo para novos estudos, e aplicações práticas por parte dos gestores de empresas que se determinam a aprofundar no campo de estudo para agregação de valor aos métodos próprios, uma vez que tal conhecimento é escasso em termos de pesquisa e pouco disseminado. 


\section{Metodologia}

A presente pesquisa define-se como revisão sistemática com abordagem qualitativa, uma vez que se propõe a analisar casos de aplicação prática do conteúdo estudado. Sampaio (2007) descreve a revisão bibliográfica sistemática como um tipo de pesquisa que utiliza fontes de dados sobre determinado tema através da aplicação de métodos de estratégia de busca, critérios de inclusão e exclusão dos estudos e síntese da informação.

O estudo foi realizado através da leitura de artigos relacionados com a Teoria das Restrições que foram filtrados em determinados critérios e selecionados, posteriormente realizado um fichamento com as principais ideias de cada artigo, e por fim uma síntese para se ter informações resumidas afim de se fazer análise e posterior discussão dos resultados obtidos com a pesquisa.

A análise foi feita com base em artigos pesquisados nos seguintes sites de periódicos de acesso aberto: Scientific Periodicals Eletronic Library (SPELL), Scientific Eletronic Library Online (SCIELO), Directory of Open Access Journals (DOAJ), a partir de pesquisas seguindo as palavras-chave: Teoria das Restrições; TOC, e utilizando filtros para seleção de apenas artigos e palavras contidas no título. Foram encontrados 51 resultados ao todo.

Para a seleção das pesquisas estudadas, foram utilizados os seguintes critérios:

- Artigos Científicos

- Abordagem sobre a TOC

- Aplicação em Indústrias

- $\quad$ Limite de ano de publicação (2009)

Do total de artigos encontrados, foram excluídos 42 artigos, pois não seguiam os critérios propostos, apesar de estarem atrelados ao estudo da TOC, haviam como foco discussão sobre o tema (24), aplicação em outros setores (10), Estudos de caso em outros segmentos (06), revisões de literatura (02), Restando somente 09 artigos que se enquadraram nos critérios. Porém, dessa quantidade, 03 estão repetidos entre as bases, dessa maneira, 06 artigos foram escolhidos para fazerem parte da análise para esta pesquisa. 


\section{Resultados e Discussões}

Apresenta-se a seguir, uma visão crítica do estudo sobre a aplicação da Teoria das Restrições em ambientes industriais, verificando os métodos utilizados para a realização das pesquisas, e os resultados obtidos com tal aplicação.

\section{Classificação das Pesquisas}

Foram elaboradas tabelas classificando os artigos científicos encontrados por base de pesquisa, título, ano de publicação, local (revista) e autores, através de software de planilhas para a separação dos dados, ordenados pelos mais recentes. Cada tabela foi inicialmente dividida pela base de pesquisa, formulando-se três tabelas com todos os artigos encontrado nas bases Spell, Scielo e DOAJ, a fim de uma melhor visualização das pesquisas contribuindo para a facilitação de uma leitura inicial, norteando para as mais prioritárias, excluindo inicialmente os artigos que evidenciavam suas características pelo título, como por exemplo, discussão de conteúdo e revisão bibliográfica, ou seja, pesquisas que não se enquadravam nos critérios e que poderiam ser excluídas inicialmente, necessitando apenas de uma leitura superficial. Os artigos que não evidenciavam a proposta a partir do título, foi necessária uma análise mais abrangente.

\section{Seleção das Pesquisas}

Ao fazer a leitura de cada artigo, foi observado que a maioria não se enquadrava nos critérios propostos mencionados anteriormente. Apenas 06 artigos tinham sua estrutura e proposta adequada para se fazerem presente neste trabalho, com prioridade em estudos que efetivamente aplicaram a TOC em ambientes industriais e que demonstram um resultado com a pesquisa realizada, mesmo que em forma de simulação, mas que propõem novos métodos de produção a partir dos pensamentos da Teoria das Restrições.

Dessa maneira, os seguintes artigos foram os selecionados para a realização do estudo, uma vez que foram observadas propostas compatíveis com os critérios de inclusão: 
Tabela 02 - Seleção de Artigos Científicos

\begin{tabular}{|c|c|c|c|c|}
\hline \multicolumn{5}{|c|}{ Artigos escolhidos para Análise } \\
\hline Título do Artigo & Ano & Fonte (Revista) & Autores & Base de Pesquisa \\
\hline $\begin{array}{l}\text { IMPLANTAÇÃO DA TEORIA DAS } \\
\text { RESTRIÇÕES (TOC) ATRAVÉS DA ÁRVORE } \\
\text { DE REALIDADE ATUAL (ARA): Estudo de } \\
\text { Caso em uma Unidade Fabril da Indústria } \\
\text { Metalúrgica }\end{array}$ & 2017 & $\begin{array}{l}\text { Revista de Estudos Sociais. } \\
\text { 2017;18(37):71-95 }\end{array}$ & $\begin{array}{l}\text { Rodrigo Javier Sólla López, } \\
\text { Dirceu Grasel }\end{array}$ & DOAJ \\
\hline $\begin{array}{l}\text { Produção enxuta e teoria das } \\
\text { restriçôes: proposta de um método para } \\
\text { implantação conjunta na Indústria de } \\
\text { Bens de Capital sob Encomenda. }\end{array}$ & 2014 & $\begin{array}{l}\text { Gest. Prod., Mar 2014, } \\
\text { vol.21, no.1, p.45-63. }\end{array}$ & $\begin{array}{l}\text { Votto, Rodrigo Goulart and } \\
\text { Fernandes, Flavio Cesar } \\
\text { Faria }\end{array}$ & Scielo/DOAJ \\
\hline $\begin{array}{l}\text { Aplicabilidade da corrente crítica da } \\
\text { teoria das restrições no gerenciamento } \\
\text { de projetos executivos de engenharia: } \\
\text { um estudo de caso em uma refinaria de } \\
\text { petróleo }\end{array}$ & 2012 & $\begin{array}{l}\text { Gestão \& Produção. } \\
\text { 2012;19(1):1-16 }\end{array}$ & $\begin{array}{l}\text { Éverton Maurer da Silva, } \\
\text { Luis Henrique Rodrigues, } \\
\text { Daniel Pacheco Lacerda }\end{array}$ & Sielo/DOAJ \\
\hline $\begin{array}{l}\text { Utilizando os passos da Teoria das } \\
\text { Restrições para a melhoria contínua da } \\
\text { produção: um estudo aplicado a uma } \\
\text { fábrica de jeans }\end{array}$ & 2011 & $\begin{array}{l}\text { Revista ADM.MADE, v. 15, } \\
\text { n. 1, p. 93-114, Janeiro- } \\
\text { Abril }\end{array}$ & $\begin{array}{l}\text { Alessandro Pereira } \\
\text { Alves, Tatiane Gomes } \\
\text { Silva, Rodrigo Santana de } \\
\text { Almeida, Samuel Cogan. }\end{array}$ & Spell \\
\hline $\begin{array}{l}\text { A Teoria das Restrições em um processo } \\
\text { de fabricação da indústria na construção } \\
\text { civil: um estudo de caso }\end{array}$ & $x^{2}$ & $\begin{array}{l}\text { Revista de Administração } \\
\text { da UFSM, v. 2, n. 3, p. 463- } \\
\text { 478, Setembro-Dezembro }\end{array}$ & $\begin{array}{l}\text { Ivana Helena de La-Rocque } \\
\text { Soares, Daniel Reis Armond } \\
\text { de Melo, Cláudio Bezerra } \\
\text { Leopoldino, Júlio Cesar } \\
\text { Andrade de Abreu, Flávio } \\
\text { Machado Moita. }\end{array}$ & Spell/DOAJ \\
\hline $\begin{array}{l}\text { A Teoria das Restrições: estudo de caso } \\
\text { em uma indústria de couros do Estado de } \\
\text { Santa Catarina }\end{array}$ & 2009 & $\begin{array}{l}\text { Revista Contemporânea de } \\
\text { Contabilidade. } \\
\text { 2009;6(11):59-82 }\end{array}$ & $\begin{array}{l}\text { Fernanda da Silva } \\
\text { Fernandes, Luciana de } \\
\text { Jesus Delfino Fernandes, } \\
\text { Renata Gonçalves Pereira, } \\
\text { Samuel Cogan }\end{array}$ & DOAJ \\
\hline
\end{tabular}

Fonte: Autores

\section{Análise de Pesquisas}

Através do estudo realizado, foi percebido que a aplicação dos conceitos resultou em ações positivas nos casos, mesmo com resistências por parte da gestão para aplicação prática e efetiva das propostas. Como o caso estudado por Cogan et al. (2011) onde relata que o método proposto se faz necessário e aplicável, porém a resistência à mudança e fatores estruturais impedem a implantação efetiva dos conceitos analisados na empresa em questão.

De uma maneira genérica os métodos utilizados para a aplicação da TOC nas pesquisas foram a identificação de problemas iniciais, identificação dos gargalos, aplicação de determinada ferramenta, e por fim os resultados obtidos. 
Tabela 03 - Análise de Resultados dos Artigos Científicos

\begin{tabular}{|c|c|c|c|}
\hline Pesquisa & Problema Inicial & Conceito da TOC aplicado & Resultado \\
\hline $\begin{array}{l}\text { Implantação da Teoria das Restrições (TOC) } \\
\text { Através da árvore de Realidade Atual (ARA): } \\
\text { Estudo de Caso em uma Unidade Fabril da } \\
1 \text { Industria Metalúrgica }\end{array}$ & $\begin{array}{l}\text { Altos Custos e Alto } \\
\text { indice de rejeição de } \\
\text { qualidade }\end{array}$ & Processo de Raciocício & $\begin{array}{l}\text { Ganhos financeiros e } \\
\text { redução de perdas }\end{array}$ \\
\hline $\begin{array}{l}\text { Produção Enxuta e Teoria das Restrições: } \\
\text { Proposta de um método para implantação } \\
2 \text { conjunta na Industria de Bens de Capital }\end{array}$ & $\begin{array}{l}\text { Lead Time alto e atraso } \\
\text { nas entregas }\end{array}$ & Processo de Raciocício & Melhor fluxo de produção \\
\hline $\begin{array}{l}\text { Aplicabilidade da Corrente Crítica da Teoria } \\
\text { das Restrições no Gerenciamento de } \\
\text { Projetos Executivos de Engenharia: Um } \\
\text { estudo de Caso em uma Refinaria de } \\
3 \text { Petróleo }\end{array}$ & $\begin{array}{l}\text { Atrasos nas atividades } \\
\text { dos projetos }\end{array}$ & Corrente Crítica & $\begin{array}{l}\text { Possibilidade de execução } \\
\text { de menor número de } \\
\text { projetos em paralelo, bem } \\
\text { como menor lead time }\end{array}$ \\
\hline $\begin{array}{l}\text { Utilizando passos da Teoria das Restrições } \\
\text { para a Melhoria Contínua da Produção: Um } \\
4 \text { Estudo Aplicado a uma Fábrica de Jeans }\end{array}$ & $\begin{array}{l}\text { Excesso de erros em } \\
\text { determinado setor }\end{array}$ & $\begin{array}{l}5 \text { passos do processo de } \\
\text { melhoria }\end{array}$ & $\begin{array}{l}\text { Possibilidade de melhores } \\
\text { resultados. Não aplicado } \\
\text { por parte da empresa }\end{array}$ \\
\hline $\begin{array}{l}\text { A Teoria das Restrições em um processo de } \\
\text { fabricação da indústria na construção civil: } \\
5 \text { um estudo de caso }\end{array}$ & $\begin{array}{l}\text { Improdutividade e } \\
\text { Gastos indesejados }\end{array}$ & $\begin{array}{l}5 \text { passos do processo de } \\
\text { melhoria }\end{array}$ & $\begin{array}{l}\text { Aumento da } \\
\text { produtividade, redução } \\
\text { dos custos }\end{array}$ \\
\hline $\begin{array}{l}\text { A Teoria das Restrições: estudo de caso em } \\
\text { uma indústria de couros do Estado de Santa } \\
6 \text { Catarina }\end{array}$ & $\begin{array}{l}\text { Produção limitada à } \\
\text { atender demanda }\end{array}$ & Processo de Raciocício & $\begin{array}{l}\text { Aprimoramento e } \\
\text { agilização do processo de } \\
\text { tomada de decisões }\end{array}$ \\
\hline
\end{tabular}

Fonte: Autores

\section{Implantação da Teoria das Restrições (TOC) Através da Árvore de Realidade Atual (ARA): Um Estudo de Caso em uma Unidade Fabril da Indústria Metalúrgica}

Foi analisada a implantação da TOC através da árvore de realidade atual (ARA), onde verificou-se a necessidade de adotar estratégias de redução de custos e de diferenciação. Foram utilizadas ferramentas para a identificação de Efeitos Indesejáveis a partir de problemas raízes, e critérios de priorização para tais efeitos, juntamente com os métodos de melhoria contínua propostas pela TOC. Usando como exemplo no caso, um dos efeitos indesejáveis identificados foi o alto índice de rejeição de produtos acabados após a montagem, consequentemente, havia um baixo volume de expedição, que gerava posteriormente uma pressão para a elevação desse volume, e para esses efeitos indesejáveis, foi realizado ação de melhoria voltado à adequação do volume programado à realidade atual da fábrica, de modo a dar foco à qualidade ao invés de volume. 


\section{Produção Enxuta e Teoria das Restrições: Proposta de um Método para Implantação Conjunta na Indústria de Bens de Capital sob Encomenda.}

No caso estudado foi observado a grande busca por estratégias por parte das indústrias de bens de capital, estratégias estas voltadas ao melhoramento do fluxo de produção e minimização de inconveniências inerentes ao sistema de produção. A pesquisa-ação foi realizada ao longo de sete anos em uma fabricante de máquinas e equipamentos para o segmento de papel e celulose, que propôs métodos para a implantação de princípios da produção enxuta e da TOC, a fim de melhorar a pontualidade de entrega (Lead Time) e reduzir o tempo de resposta. Alguns processos de melhoria foram realizados gradativamente, como a reorganização do layout da fábrica, alocação de recursos para produção em ritmo simultâneo, redução do volume de estoque. Voltada para a TOC, ferramentas como método DBR (TamborPulmão-Corda) e 5 passos para melhoria contínua, foram evidenciados nesta pesquisa-ação, junto aos conceitos da produção enxuta. A proposta foi testada na empresa em questão, não havendo a implantação permanente, mas evidenciando os resultados que podem ser gerados quando aplicada.

\section{Aplicabilidade da Corrente Crítica da Teoria das Restrições no Gerenciamento de Projetos Executivos de Engenharia: Um Estudo de Caso em uma Refinaria de Petróleo}

O método utilizado na pesquisa em questão foi a Corrente Crítica da TOC aplicada em uma refinaria de petróleo, a fim de se estudar o ambiente multiprojeto que pode resultar em atrasos nas atividades. Foi realizada a classificação de etapas a serem seguidas para a implantação da corrente crítica: A definição das atividades, Construção de estimativas de tempo, programação dos recursos, utilização e dimensionamento dos pulmões de tempo, construção de cronogramas individuais, identificação do recurso restritivo, programação multiprojeto e por fim, monitoramento dos projetos.

Utilizando os Passos da Teoria das Restrições para a Melhoria Contínua da Produção: Um Estudo Aplicado a uma Fábrica de Jeans

A pesquisa em questão traz a aplicação da TOC através do método de focalização em cinco passos para a melhoria, onde foi possível a identificação e eliminação de determinada 
restrição no sistema. O estudo foi realizado em uma indústria de fabricação de jeans e teve como propósito a investigação dos principais problemas no processo produtivo. Os resultados apontaram que o excesso de erros no setor de costura era a restrição do sistema, uma vez que esse processo atrasava todo o restante da linha produtiva, já que a produção depende da fabricação de peças em postos anteriores. Tal grupo produzia bem abaixo da meta estabelecida, interferindo na produção contínua. O estudo possibilitou a aplicação efetiva, ainda que evidenciado os ganhos, porém imposições e resistência por parte dos gestores fizeram que houvesse apenas a investigação, sem a real implantação.

\section{A Teoria das Restrições em um Processo de Fabricação da Indústria na Construção Civil: Um Estudo de Caso}

Este artigo apresenta uma proposta de melhoria para uma indústria de fabricação de lajes pré-fabricadas, uma vez identificado gargalo que impedia maior desempenho produtivo e gastos com horas extras.

O presente estudo, também se fez da utilização da aplicação do método de focalização em cinco passos para a melhoria contínua, através da identificação da restrição utilizando o cálculo de capacidade, onde foi possível identificar que a atividade do ferreiro necessitava maior capacidade para atender a sua demanda; explorando a restrição com a alocação de operários para a atividade RRC, bem como na organização de layout mais eficiente; subordinando os demais recursos à restrição; elevando a restrição através da utilização de horas extras e por fim, evitando a inércia do sistema, uma vez eliminada a restrição.

\section{A Teoria das Restrições: Estudo de Caso em uma Indústria de Couros do Estado de Santa Catarina}

Teve como proposta evidenciar de forma empírica a aplicação da Teoria das Restrições para a tomada de decisão. Realizado em uma indústria de couros, o estudo observou que há restrições no processo, e propôs a maximizar os ganhos a partir delas. Em uma primeira instância, viu-se a necessidade de observar o nível de conhecimento dos gestores para com o tema em questão, para então aplicar as propostas, uma vez que a implantação delas é de certa forma pouco impedida quando se tem conhecimento por parte da alta gestão. 
Assim, foi aplicado a TOC em duas vertentes no setor produtivo: Aplicação com restrição na capacidade de produção, e aplicação com restrição na matéria-prima. Em relação à restrição na capacidade produtiva, verificou-se que existia um pedido que não era possível atender, uma vez verificada a incapacidade de produzir aquela quantidade de lotes demandados, para isso, a TOC auxiliou na administração através da identificação do gargalo, se propondo a aumentar a capacidade através da aquisição de um novo equipamento. Observando a restrição como matéria-prima, o estoque de couros era cada vez mais reduzido, tanto por conta da sazonalidade e também por questões de períodos de redução. A proposta para a aplicação de melhoria nesse caso foi o aumento em pequenos volumes nos pedidos de maior aproveitamento do couro, através da apuração das classes de couro de maior ganho. Por fim, o estudo proporcionou auxílio na tomada de decisão e agilização nos processos a partir dos pressupostos estabelecidos pela teoria, evidenciando a maximização dos ganhos e redução de inventário.

\section{Considerações Finais}

O presente trabalho permitiu observar a aplicabilidade da Teoria das Restrições em ambientes industriais: em relação aos métodos para se implantar tais conceitos, os resultados que se obteve em termos de produção, os impactos que a aplicação causará adotadas determinadas medidas, e a captação dessas estratégias por parte dos gestores. Foi possível verificar que a TOC proporciona um novo modelo de produção, e que resulta em caminhos positivos e resultados satisfatórios em curto ou longo prazo, ainda que seja necessária uma certa mudança, tanto para o ambiente aplicado (estrutura), quanto para a gestão da empresa, principalmente quando não se tem algum conhecimento teórico sobre as ferramentas propostas, como relatam Goldratt e Cox (2002, p. 364), onde "um dos maiores obstáculos para uma implementação bem-sucedida é superar a resistência à mudança. A chave está em saber como orientar a dinâmica da interação entre pessoas com diferentes objetivos e níveis de entendimento".

De modo geral, nos ambientes de estudo, foi utilizado o processo de raciocínio da TOC como um todo, assim como também houveram aplicações de ferramentas específicas a partir da análise dos pesquisadores, que observaram a oportunidade de melhoria através de tal método 
adequado a cada caso, obtendo ganho no sistema produtivo: a exemplo dos 5 passos para a melhoria contínua, e o método tambor-pulmão-corda, conceitos que se encaixaram em alguns dos sistemas estudados, mesmo que não implantados e não estabelecidos efetivamente nas organizações em estudo, mas que propuseram caminhos para se alcançar maior desempenho proporcionando resultados positivos.

\section{Referências}

ALVES, A; SILVA, T; ALMEIDA, R; COGAN, S. Utilizando os Passos da Teoria das Restrições para a Melhoria Contínua da Produção: Um Estudo Aplicado a uma Fábrica de Jeans. Revista ADM.MADE, v. 15, n. 1, p. 93-114, 2011.

BORGES, R.S.G.; MARQUES, A.L., Gestão da Mudança: Uma alternativa para a avaliação do impacto da mudança organizacional. Revista Administração Faces Journal, v. 2, n 1, p. 95-113, 2011.

CHECOLLI, P.F; Aplicação da teoria das restrições em linha produtiva. 2000. Dissertação (mestrado) - Universidade Federal de Santa Catarina, Programa de pós-graduação em administração. 2000. Disponível em: <https://repositorio.ufsc.br/xmlui/handle/123456789/78762>. Acesso em: 25 de março 2018.

CHOI, M. Employees' attitudes toward organizational change: a literature review. Human Resource Management, v.50, n.4, p.479-500, 2011.

CORBETT, T. Contabilidade de ganhos: a nova contabilidade gerencial de acordo com a teoria das restrições. São Paulo: Nobel, 1997.

CORBETT, T. Bússola Financeira: o processo decisório da teoria das restrições. São Paulo: Ed. Nobel, 2005.

COX III, J. F; SPENCER, M. S. Manual da Teoria das Restrições: Prefácio de Eliyahu M. Goldratt ; tradução Fernanda Kohmann Dietrich. - Dados eletrônicos. - Porto Alegre : Bookman, 2008.

COX III, J. F; SCHLEIER, J. G ; Handbook da teoria das restrições [tradução: Beth Honorato ; revisão técnica: Aline Dresch ... et al.]. - Dados eletrônicos. - Porto Alegre : Bookman, 2013.

DUCATTI, A. P. S. Contribuições da teoria das restrições para gestão da mudança. 2014. $101 \mathrm{f}$. Dissertação (mestrado) - Universidade Estadual Paulista Julio de Mesquita Filho, Faculdade de Ciências, 2014. Disponível em: <http://hdl.handle.net/11449/110924> Acesso em: 26 mar. 2018.

FERNANDES, F et al. A Teoria das Restrições: Estudo de Caso em uma Indústria de Couros do Estado de Santa Catarina. Revista Contemporânea de Contabilidade. V. 1, n. 11, p. 59-82, 2009.

GERHARDT, T. E; SILVEIRA, D. T. Métodos de pesquisa. Série educação à distância. 1.ed. Porto Alegre. Editora da UFRGS, 2009. 
GIL, A. C. Como Elaborar Projetos de Pesquisa. 5. ed. São Paulo: Atlas, 2010.

GOLDRATT, E. M.; Cox, J. A Meta. 4ª ed. rev., São Paulo: Claudiney Fullmann, 1990.

GOLDRATT, E; COX, J. A Meta: Um processo de melhoria contínua. São Paulo: Nobel, 2002.

GOLDRATT, E. M.; COX III, J. F. A Meta. 28.ed. São Paulo: Educator, 1996

GUERREIRO, R. Os Princípios da Teoria das Restrições sob a ótica da mensuração econômica. Scielo. Caderno de Estudos nº13, São Paulo, 1996.

LÓPEZ, R; GRASEL, D. Implantação da Teoria das Restrições (TOC) Através da Árvore de Realidade Atual (ARA): Um estudo de Caso em uma Unidade Fabril da Indústria Metalúrgica.

R, SAMPAIO; M, MANCINI. Estudos de Revisão Sistemática: Um guia para síntese criteriosa da Evidência Científica, Revista Brasileira de Fisioterapia, Vol.11, 2007.

SILVA, E; RODRIGUES, L; LACERDA, D. Aplicabilidade da Corrente Crítica da Teoria das Restrições no Gerenciamento de Projetos Executivos de Engenharia: Um Estudo de Caso em uma Refinaria de Petróleo. Gest. Prod. São Carlos, v. 19, n. 1, p. 1-16, 2012.

SOARES, I. et al. Teoria das Restrições em um processo de fabricação da indústria na construção civil: Um estudo de Caso. Revista Adm. UFSM, Santa Maria, v. 2, n 3, p 463-478, set/dez. 2009.

SOUSA, F; PIRES, S. Produzindo para disponibilidade: Uma aplicação Teoria das Restrições em Ambientes e Produção para Estoque. Gest. Prod. São Carlos, v. 21, n. 1, p. 65-76, 2014.

VIDAL, S; WANKE, P. Teoria das Restrições: Principais conceitos e aplicação prática. 2009.Disponível

em:<www.unicap.br/...PRODII_RESUMO_16_TOC_ARTIGO_PETER_WANKE.doc>. Acesso em: 21 mar. 2018.

VERMA, R. Management science, theory of constraints/optimized production technology and local optimization. Omega, International Journal of Management, v.25, n.2, p. 189-200, 1997.

\section{Como citar este artigo (Formato ABNT):}

SIMÕES, João Vitor Batista; LIMA, Antonio Raniel Silva. Aplicabilidade da Teoria das Restrições: Um Estudo dos Métodos de Gerenciamento da Produção em Indústrias. Id on Line Rev.Mult. Psic., 2018, vol.12, n.42, Supl. 1, p. 282-299. ISSN: 1981-1179.

Recebido: 02/11/2018;

Aceito: 05/11/2018 